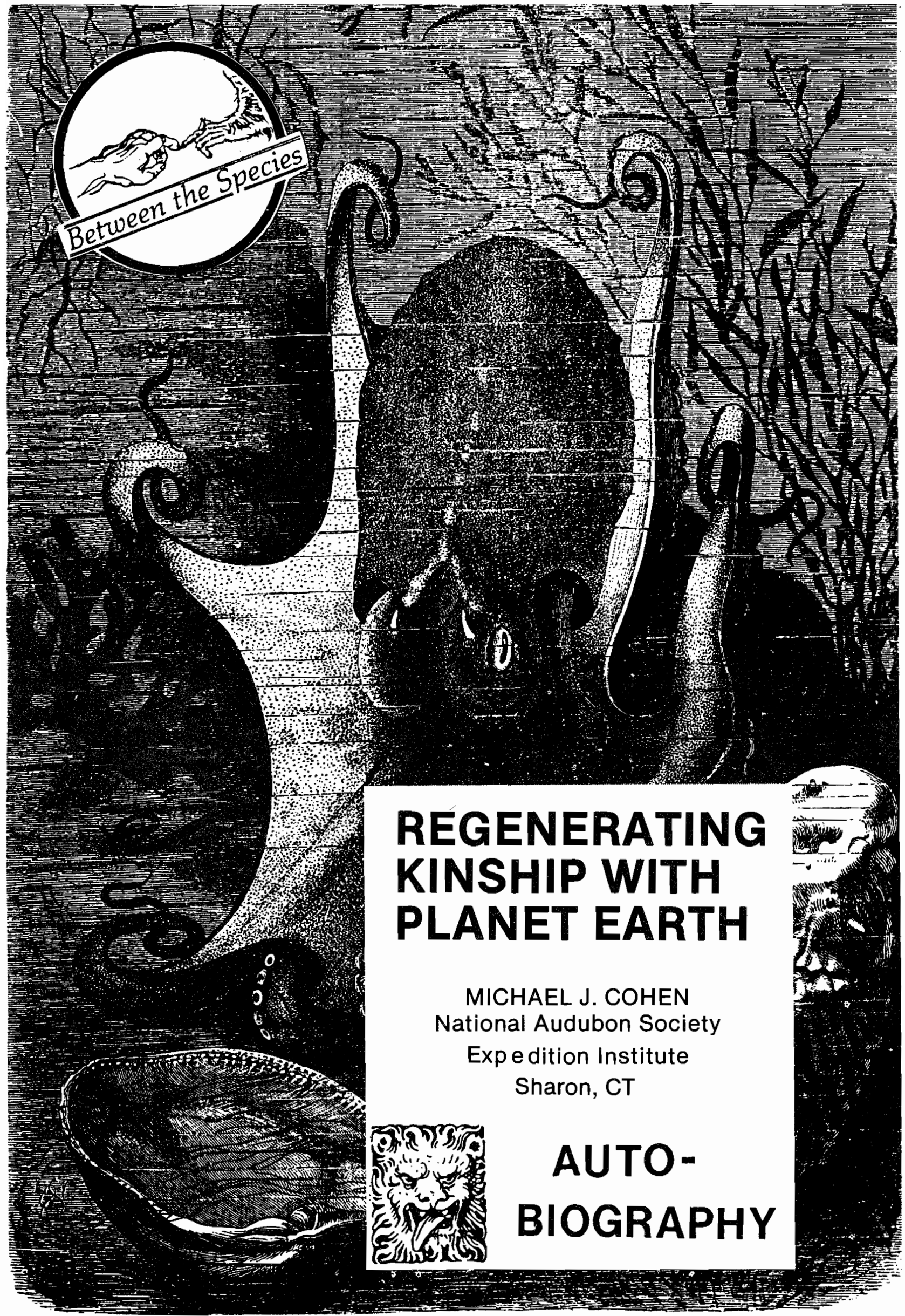


In 1959 I walked into wild America. I left the familiar indoor world of biology teaching, counseling, traditional music and recreational administration. I wanted to establish a new program that allowed me to practice these skills outdoors. I knew I worked best and felt best living and teaching in natural settings. I knew I compromised myself working and living elsewhere. That's why I became an outdoor educator.

Although the risk bothered me in my dreams, daytimes I felt confident leaving the mainstream world I knew so well. I respected nily decision because during my childhood I'd learned to trust my deeper feelings. I was born left-handed. As a kid, and for my first five years of school, I was required to wsite "righty." But it never felt right. I never wrote well. Constantly, "childishly," I argued my case for writing lefty because it felt easier. Finally, by sixth grade, they let me do it. Within the year I surpassed my right-handed penmanship skills. I learned that I had been right all along. From this and similar experiences I learned to honor how I felt and to trust what my feelings told me. When I moved into the countryside, nature strengthened my trust in feelings and thereby entered my consciousness.

\section{Learning from Nature}

Since 1959, as part of the small accredited educational travel community I established, I've constantly camped out, sleeping on the ground at night, sanetimes in tents, often under brilliant winter stars. My laboratory is the face of North America, my teacher the life experience in the wilderness and sub-cultural settings I visit from Newfoundland to California. Unlike my traditional education, the natural world further encourages me to respect my sensations, thoughts, feelings, and actions. Same people say I've been in the woods too long, but the state of the environment tells me that too many of us have not been there long enough. From nature I learn that most of our psychological, social, and international unrest grows out of our deep conflicts with the natural world.

Over a period of 20 years my independent outdoor program grew and became the B.S. and M.S. degree programs of the National Audubon Society Expedition Institute and Lesley Col- lege. On our expeditions, from real-life encounters we learn to emulate the global life system's ways. We learn experientially from our actions, from our senses and feelings, from the people we meet, the places we travel to, books in libraries all across the country, our classmates' and guides' reactions to us, our knowledge from previous years, and the sensations of nature. We learn peaceful co-existence by building it. Far from a collection of unrelated academic subjects, our small consensus based expedition commities organize their encounters to cover most disciplines, find new values in living and learning, and explore the immense land and diverse people that make up this place we call America.

\section{Planet Earth as a Living Organlsm}

A spectacle of cliffs and color mark where Bright Angel Creek joins the Colorado River in the bowels of Grand Canyon National Park, 4000 feet below the rim. Here multibillion year old granite-veined schists portray the birth and changes of ancient landscapes. And here in 1967, one scorching day, a thunderstorm, and a bag of potato chips sowed in me the idea that Planet Earth is a living organism.

The storm washed the steep canyon walls with flowing red clay mud. The colorado River's inner gorge looked like waterfalls of blood spilling into the river artery. Eating potato chips (in order to regain salt lost through sweating on the 110 degree hike into the canyon), I watched the storm's drama in awe from iny shelter. I felt the inner canyon quickly cool, just as my sweat-cooled skin had felt on my hike into the blazing canyon hours before. At that moment, Planet Earth touched me in a new way. For the first time I sensed I was witnessing the metabolism of a living being, not just mechanics of geology and weather systems.

My classrocm, wild America, for an instant had cracked a long established wall in my mind. It set me thinking of the planet as a living organism instead of as an inert resource or machine-like spaceship. That spark of thought but a small feather of insight floating on an immense ocean of highly trained Newtonian outlooks. But like colored sunglasses, the feather created a new perspective. Soon my curiosity asked: if the river's salts and sediments continually 
run into the sea, why is the sea not salty. near lifelessness as at the Great Salt Lake? Similarly, how does my body know to regulate its salt content from my potato chip intake? Walter B. Cannon had written about "homeostasis" in my Physiology 101 book, The Wisdam of the Body. Was there a wisdom of the planet?

Now the thunderstorm's cooling effect coaxed me to ask, "Why do neither I nor the planet become too hot or too cool for life to continue? Was it for self-preservation that the Earth cooled itself as my sweat had cooled me? If while I was hiking I'd found an icicle hanging in the broiling canyon, I'd have thought it a miracle. Yet I took for granted the homeostatic life powers that kept me cool in the desert's heat. Was planet earth alive like me?"

The earth a living organism? That tinge of thought became a stubborn unspoken question. Like an ember fanned by the wilderness wind, it grew stronger over the following decades of camping outdoors year round. In time I discovered that biologically the planet and I function identically. If I'm alive, it's alive.

Unaware of the thoughts and findings of others, by 1981 I interpreted ecosystems and created curriculums and courses as if Planet Earth lived. The interpretation precipitates phenomenal holistic growth in our Audubon Expedition Institute students due to planetperson congruency, wherein people's biology and the planet's life are one and the same. (Although admittedly, it's difficult to see how the planet scratches when it itches.)

An Expedition participant's essay describes the living planet: "Yesterday I daydreamed that I was wilderness. I was alive. I grew bigger and bigger until I became the whole Earth. I felt I was the

planet; I felt just like myself except I couldn't talk words. But I could feel. And if I felt too hot I'd cool myself by enlarging my cloud cover and oceans, or create storms, move my glaciers or remove some of $\mathrm{my}$ atmospheric $\mathrm{CO} 2$ blanket. If the air felt stuffy I'd swallow carbon and release fresh oxygen. If my oceans got too salty I'd remove the salt by moving continents to form warm, shallow settling and evaporating seas. If I was hungry or thirsty, I'd eat sunshine or think up a storm. I felt like E.T. and had his powers. It felt strong and right. I felt proud for inventing organs that recycle my excrements into healthy food and water. I enjoyed being a fertilized growing egg of the universe and good about all aspects of my survival. I was never bad, wrong or negative. I was an action. I felt important and secure because I survived even when I slept; and the global life commuity insisted that I breathe even if I chose not to. I congratulated myself for creating and maintaining life without using words, numbers or money. I felt in control and peaceful."

I find that if I treat the earth as if it was dead, it looks and acts dead. But when I treat it as if it lives, it acts alive. Thus, my attitude and actions can determine whether a wetland becomes a parking lot or remains a nurturing cradle of life.

In sumary, extended living and learning in natural and subcultural settings teaches me that like myself our planet is a pulsating and sentient living organism. The earth is a giant cell, a collective ongoing statement of each individual entity's ability to enter relationships that organize, preserve, and regenerate themselves.

\section{Feelingful Interactions Sustain Global Harmony}

The planet as a global organism provides excellent instruction about the life process. one typical lesson took place while I was by myself on a short solo in Newfoundland!s Gros Morne National Park. Plagued by everyday problems and expectations that filled my mind. I sat alone high on a rock face overlooking the grandeur of Western Brook Fjord. As I admired the spectacular array of woodlands, cliffs, and lakes, the distractions of daily life faded. Soon a gentle breeze alerted me that I ignore the air. I look through it, not at it. I overlook that nature's art includes the atmosphere. I attempted to sense this. Closing my eyes, I listened to myself breathe, savoring each life preserving exchange between myself and the planet. This conscious connection with the natural world relaxed me. It helped me catch up with myself. For the moment, nature's forces erased the tensions arising from my memory's expectations and conflicts with the present.

After a while, for a reason unknown, I 
purposely stopped breathing. (Did the planet signal me to do this?) Gradually I felt a new tension build. I felt my body cry for air. Finally, my earth-inherited survival feelings demanded that I breathe again. I did. The release of tension felt wonderful. It helped me senge great truths. It affirmed that the planet communicates erotically through same level of tension producing and tension releasing sensations. It no doubt has done so since its beginnings. Without words or numbers, the earth conveys information. It tells me to breathe and share my life for our mutual existence. Later. I learned that the words "spirit" and "psyche" derive from "respirate:" to breathe.

\section{Implications of Person-Planet Oneness}

I like relating, I decide that because I am conceived from and similar to the planet, in some measure my desire for the rewards of tension releasing relationships must also exist in atomic and planetary orbits, in the seasons, organisms, and life systems like mountains, clouds, and tides. I and others suggest that nature is the product of each entity's desire to share, preserve, and regenerate itself through self-organized stabilizing tension releasing relationships. This desire, a universal affinity, undoubtedly creates a knowledgeable global consciousness; a unifying communion that coordinates the natural world's survival. It's what heals an injured finger or landscape without people's direction. And because in the global collaborative all entities relate, waste products and garbage don't exist. Since its ancient beginning the planet's affinity relationships have created a fluctuating but harmonic life

system perfection.

My recognition of the planet as a living organiam like myself opens new perspectives for me. For example, competition. Just as the organs and entities that make up my body don't compete with each other for survival, neither do the wild entities that constitute the planet compete. Wildlife, best able to cooperate with its neighboring environs, gains support and retains its life as a vital organ for the planet's health. Less supported wild entities change their forms and affinity relationships until they too coopertively support the global life community. verative, mutually beneficial relations, not competition, underlie the global and local survival process.

\section{Underlying Causes of Disharmony: Th Abandonment of Nature}

While camping deep in a beautiful and serene southwest canyon wilderness, I watched modern Americans arrive there by yacht across a power darmed portion of the once wild colorado River. To my amazement they disembarked with golf clubs in hand and commenced practicing their golf swing. They drove golf balls against ancient, cathedral-like, petroglyphed cliff walls which conveniently bounced them back. Stunned, I soon recognized that these people were repeating our wilderness history. They were acting out our culture's accumulated relationship with nature.

This incident forced me to question my mainstream upbringing. Unlike other cultures, why do we place so little emphasis upon sentient wilderness values in comparison to cognitive "left brained" learning like the 3 R's and objective facts?

Scientists tell us that humanity evolved in a tropical, womb-like environment-probably East Africa. There, for survival more intense consciousness and tool use were early humanity's major adaptive device. Obviously. as these early people migrated from the tropics into the more northerly, four-seasoned enviromments, they experienced a greater survival stress because their hairless bodies and cultural habits evolved to share the supportive tropical climate, not the food

\section{scarce temperate winters.}

Same migrating groups coped with seasonal challenges nomadically. They moved to warmer places during the winter and to new food areas when they depleted old ones, allowing depleted food areas to renew themselves. For them, knowledge became an erotic consciousness of the global organisn's motions, of what, when, and where food and shelter were available. Their lives flowed with nature's tension releasing fluctuations and cycles. Like the American Indian, they thought nature's pulse consisted of powerful life giving spirits such as wind, rain, clouds, and landscape features. They created living earth rituals and long lasting lifestyles, adapting them to the natural world's ancient self-organized relationships. 
My upbringing tells me that my ancestors were not these people but were instead other tropical migrating groups. My ancestors pioneered modern civilization. They devised a different means for survival. They seldom learned intimately from their new habitats nor flowed with the seasonal temperatures and food conditions. Instead, their memories, myths, and feelings kept alive in fantasy the womb-like relatively stable tropical environment of their origin. Unlike their "uncivilized" counterparts, technologically they superimposed their tropical memories on their new climatic surroundings, thereby changing that landscape. Instead of joining natural systems' ways, they civilized them. Their culture primarily worshipped their cognitive survival mechanisms, their mentality womblike memories and tropic-simulating technologies. These fortressed them against the more fluctuating, erotic natural world. By this means they survived.

For our ancestral, pre-Western cultures the earth's pulsating life systems became grist to build artificial womb-like tropical environments anywhere. Today their powerful symbols, images, and technologies have become a juggernaut alarmingly separated from the time-tested ways of the natural world. The natural entities and native peoples we learn to pry or blast from their ancient life partnerships become garbage, pollutants, or eradicated. Unfortunately, mainstream people who dig wilderness the most have bulldozers.

\section{Disciplining Natural Life Systems}

Infants are born with living earth affinity feelings like love, hunger, thirst, breath, harmony, and excretion. For growth and survival, like a placenta, these inherited feelings connect infants' metabolisms to the planet's physiological womb of water, minerals, air, food, temperature, and companionship desires. (Obviously we don't inherit these feelings from a dead planet, for dead matter is devoid of such sensations and growth desires.)

I recognize that the wilderness biology and feelings within me evolved with the earth over billions of years. At birth and prebirth I knew only nature's callings,' not the ways of society. But my Western upbringing taught me to demean my natural tension releasing feelings and tendencies to favor my culture's mannerisms. For example, my hunger for food translates into dependency on money, food stores, shopping, table manners, transportation, advertising, and three meals a day; my excretion was toilet trained, my left-handedness restrained. Our society's artificial meanings were imposed upon my innate global consciousness. I believe our environmental problems stem from subconsciously excessively disciplining the natural world as was our nature excessively disciplined during childhood.

\section{Creating Our Artificial World}

In order to make us change the natural world into the tropics, modern civilization trains our perceptions and carves our consciousness. For example, as you now read this page, out of habit and training you pay attention only to the words upon it, not the environment. You are not now conscious (as perhaps you were when a child) of the individual letters on this page or the page itself. As I confront you with this fact, you become aware of the individual letters and white page. Yet they disappear if you continue to read. In this way words usually limit or distort reality. This limitation becomes a perpetual habit as ingrained as language itself.

Because average Americans spend over $95 \%$

of their lives in artificial tropical simulations like houses, offices, and schools, we know the natural world not by our experience with it but by our limited words describing it. For example, when people discover that life is undefinable, they don't really know what life is. Even though they are life, they've learned to know themselves through symbols and technologies, not experiences and sensations. Until we discover and use holistic processes to relieve our problems of artificial life, we attempt to solve these problems artificially, with the same words and means that caused them. It's like accidentally drilling a hole in the floor of a boat, watching water rush in, and then drilling another hole in the floor to drain out the water.

\section{Repairing Civilized Disorder}

I and others honor the joys we've found living outdoors. Often I compare them to the anxieties and expectations I gained from my civilized upbringing. The comparison lets me 
see how our civilization causes our disorders and stress.

Because the living earth's physiology includes our personal inner biology and emotions, as we attack the earth to create the likes of the tropics, we also attack the nature within us. our inner nature responds to its abandonment with aggression, anxiety, or depression. Moreover, once we are conditioned to habitually think in our exploitive western ways, we continually carry our attack upon nature with us, no matter where we are. And because objective science usually negates our feelingful inner nature, science becones part of the stress problem.

Experiential educators can help correct our society's disharmony. Unlike traditional acadenics, experiences evoke feelings and actions as well as thoughts. That's why experiences are the best teacher. But to avoid harmful conflict, our experiential education symbolizations must reunite our inner nature with the sentient living earth. only when feeling and nature symbols synchronize does our mentality touch the earth's wisdom and enjoin us with life's regenerative powers. Only then we learn that the stress on the land and wildlife is the same stress we suffer.

At the Audubon Expedition Institute we relieve stress by encouraging students to choose acts that:

(1) recognize planet earth as a selforganized living organism which inhabits us biologically and emotionally,

(2) validate our natural sensations, feelings, and reverence for life; let us substitute the word nature for feelings,

(3) help us recognize that affinity feelings about our natural selves or nature are global survival feelings; our negative or stress feelings are our inner planet's reaction to being abandoned,

(4) satisfy our natural feelings without excessively using technologies; give us confidence in the planet's self-organized, sentient survival wisdam,

(5) engage in technologies and lifestyles which give joy while harmonizing with nature and therefore produce no garbage or
(6) satisfy our natural survival feelings rather than our artificial (acculturated) feelings or womb-like tropical memories; recognize feelings as facts,

(7) are based upon choice rather than habit or conditioning; differentiate between our human and earth mothers,

(8) celebrate the natural world within and around us and in others; recognize cooperation and peace as functions of nature,

(9) feel comfortable as these acts are measured by their long-term effects on nature and humanity and their ability to support life; recognize nature's role in every act,

(10) teach us about our shared nature and kinship with planet earth as a living organism; environmentally re-educate us by validating nature's timeless life-wisdom,

(11) confront and subdue cultural fears and prejudices against nature within and without ourselves and in others,

(12) disengage us from stressful past and future messages or expectations by focusing on the now of life (nature).

(13) disregard media messages that demean or victimize nature within or without; make life and the landscape sacred; teach us to commune with nature,

(14) give us security based upon our ability to laugh at modern society's shortcomings, create good feelings about ourselves as natural beings, strengthen our natural attributes and our culture's survival responsibilities,

(15) establish counseling or stress resolution settings that identify our nature, positive feelings, emotions, and experiences with those of the living planet,

(16) establish nature congruent symbols, communities, interpersonal relationships, and wilderness experiences,

(17) counteract our civilization's desire to excessively use the remaining natural world as grist for converting the temperate and arctic zones into "tropic-like" environ- 
(18) make physical and psychological space to reconnect our nature within to the wilderness community,

(19) help us recognize our society's effects upon ourselves by measuring its effect upon the natural world,

(20) celebrate nature-enhancing cultural differexces and diversity; provide equal time for nature at home and school; recognize consciousness as a planet function.

\section{Conclusion}

Let us not in futility dance on the planet's sickbed. Instead, let's help it heal itself by healing our relationship with it.

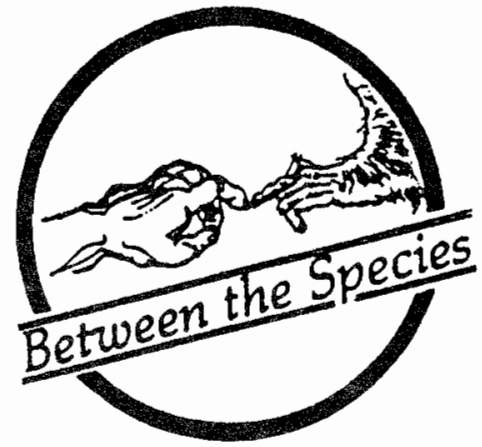

Bibliography

Cohen, Michael, our Classroom Is Wild America (Cobblesmith, 1975).

- Prejudice Against Nature: A Guidebook for the Iiberation of Self and Planet (Cobblesmith, 1982).

- As If Nature Mattered: A Naturalist Guided Tour Through Hidden Valleys of Your Mind (National Audubon Society Expedition Institute, 1985).

Cohen, et. al, Proceedings: Is the Earth a Living Organism? (NASEI, 1986).
DEGREES

IN INTERSPECIES STUDIES

Correspondence study in Interspecies Studies is available through the Center under the general supervision of Professor Steve Sapontzis, author of MORALS, REASON AND ANIMALS, recently published by Temple University Press. Available offerings provide both for those persons who may want to enroll in a single correspondence offering as well as for those who want a coherent degreeequivalent program. Persons wanting to earn a Bachelor's, Master's, or Doctorate in Interspecies Studies may do so through an arrangement between the Center/San Francisco Bay Institute and Columbia Pacific University. With 5500 students, the University is the largest academic institution in the United States based wholly upon correspondence wo $k$. In these degree programs credit is also awarded for relevant job experience, studies elsewhere, and features an Independent Studies Project designed jointly by the student and a faculty mentor. No residence is required. Please request a detailed brochure from the San Francisco Bay Institute, P.O.Box 254, Berkeley, CA 94701, USA or phone 415/526-5346. Inquiries from outside the U.S. are welcome.

The program is administered by John Stockwell, Co-editor of Between the Species and Director of the Institute.

A pamphlet, DEGREE PROGRAMS IN ENVIRONMENTAL AND 